Canadian Journal of Fisheries and Aquatic Sciences

Canadian Science Publishing

Journal canadien des sciences halieutiques et aquatiques

\title{
Optimal sampling methods for modelling the occupancy of Arctic Grayling (Thymallus arcticus) in the Canadian Barrenlands
}

\begin{tabular}{|r|l|}
\hline Journal: & Canadian Journal of Fisheries and Aquatic Sciences \\
\hline Manuscript ID & cjfas-2016-0429.R1 \\
\hline Manuscript Type: & Article \\
\hline Date Submitted by the Author: & $16-$ Dec-2016 \\
\hline Complete List of Authors: & $\begin{array}{l}\text { Baker, Leanne F.; University of Waterloo, Biology } \\
\text { Artym, Kyle; University of Waterloo, Biology } \\
\text { Swanson, Heidi; University of Waterloo, Biology }\end{array}$ \\
\hline Keyword: & $\begin{array}{l}\text { occupancy model, spatial replication, electrofishing, Arctic Grayling, } \\
\text { correlated detections }\end{array}$ \\
\hline
\end{tabular}


1 Title: Optimal sampling methods for modelling the occupancy of Arctic Grayling (Thymallus arcticus) in

2 the Canadian Barrenlands

3

4 Authors: Leanne F. Baker ${ }^{1,2}$, Kyle J. Artym ${ }^{1,3}$, and Heidi K. Swanson ${ }^{1 *}$

$5 \quad{ }^{1}$ Department of Biology, University of Waterloo, 200 University Ave. W., Waterloo, Ont., Canada, N2L

$6 \quad 3 G 1$

$7 \quad 2$ bakerleannef@gmail.com

$8 \quad 3$ kartym@uwaterloo.ca

9 *Corresponding author. Email: heidi.swanson@uwaterloo.ca, Telephone: (519) 888-4567 (ext. 37387),

10 Fax: (519) 746-0614

11

12

13

14

15 Number of tables and figures: 1 table, 5 figures

16

Number of references: 30

17

18

19

20

21

22

23 


\section{Abstract}

25 In occupancy models, imperfect detectability of animals is usually corrected for by using temporallyrepeated surveys to estimate probability of detection. Substituting spatial replicates for temporal

27 replicates could be an advantageous sampling strategy in remote Arctic regions, but may lead to serious

28 violations of model assumptions. Using a case study of site occupancy of adfluvial young-of-year Arctic

29 Grayling in Barrenland tundra streams, we assessed reliability and efficiency of alternative sampling strategies; i) randomly distributed vs sequential adjacent spatial replicates; ii) visual vs electrofishing

31 surveys; and, iii) spatial vs temporal replicates. Sequential, adjacent spatial replicates produced spatially

32 auto-correlated data. Autocorrelation was relieved using randomly distributed spatial replicates, but using these randomly distributed spatial replicates introduced significant error into estimates of the probability of occupancy in streams. Models designed for spatially-autocorrelated data could minimize this bias. Visual and electrofishing surveys produced comparable probabilities of detection. Spatiallyreplicated surveys performed better than temporal replicates. The easiest and relatively most cost-

37 effective sampling methods performed as well as, or better than, the more established, expensive, and 38 logistically difficult alternatives for occupancy estimation. 


\section{Introduction}

Freshwater ecosystems in the Arctic are experiencing rapid change in climate, and increasing pressure from ever-growing industrial development. The impacts of anthropogenic stressors on hydrology, water temperature, primary productivity, food web structure, and fish life history are expected to be far-reaching, but have been poorly quantified in these remote and under-studied ecosystems (Prowse et al. 2012, Reist et al. 2006a, Wrona et al. 2006). Comprehensive, standardized datasets are needed for larger-scale integration of data (Reist et al. 2006b), but studies to date on northern fishes have used a multitude of methods and data analysis tools that preclude synthesis on large spatial or temporal scales. Reliable monitoring programs can be costly in terms of both financial and personnel resources; thus, the development of a cost-effective data collection framework for sensitive northern fish populations is essential to their conservation.

In the Barrenlands region, adfluvial populations of Arctic Grayling (Thymallus arcticus, Pallas), like other migratory fishes, are sensitive to fragmentation or alterations of the habitats they utilize (Reist et al. 2006b). Young-of-year Arctic Grayling hatch and rear for several months in clear, cool, gravel or rock-bottomed streams (Scott and Crossman 1973) before migrating to overwintering sites in lakes (Jones and Tonn 2004). The Barrenlands landscape is a priority research area for many northern stakeholders including industries, regulators, and Indigenous groups working to mitigate effects of mineand/or climate-related stream dewatering on populations of adfluvial Arctic Grayling. Despite this, habitat use by young-of-year, adfluvial Arctic Grayling in the Barrenlands has only been investigated in a handful of streams (e.g., Jones and Tonn 2004).

Occupancy, defined as the proportion of area, patches, or sample units that are occupied (i.e., species presence) by a given species, is a natural state variable that can be used in studies of species distribution and range. Occupancy models are a means of deriving information regarding the ecological 
niche of a species (e.g., Hutchinson 1957), as each species has a unique set of requirements that must

71 be provided by habitats used. Identification of key habitat variables that species respond to can be used

72 to develop habitat models that predict patch and landscape-level occupancy (e.g., see Verner et al.

73 1986; Scott et al. 2002). In remote northern environments, it may be particularly advantageous to apply

74 an occupancy modeling framework (MacKenzie et al. 2002) to monitoring programs of landscapes that

75 are too large and logistically difficult to survey extensively. Time and effort spent sampling a site can be

76 reduced by focusing sampling efforts on collection of presence-absence data (instead of abundance

77 data) in a manner that permits inference to the entire area of interest, allowing greater spatial and

78 temporal coverage of a species' distribution across the landscape (Royle and Nichols 2003). Occupancy

79 modeling also explicitly addresses issues of imperfect detection (i.e., false absence) (Mackenzie et al.

80 2002). Failing to account for false absences can introduce significant error into species distribution

81 models (Gu and Swihart 2004).

The standard method for estimating detection probabilities in occupancy studies involves surveying a site multiple times over a defined 'season' (MacKenzie et al. 2002). Temporally-replicated

84 surveys can be expensive and logistically difficult to implement in remote areas, and resources invested 85 in visiting the same site multiple times within a given timeframe and budget limits spatial coverage of

86 survey efforts. This may be especially problematic in surveys of Arctic fishes because repeat visits must

87 be made within the relatively short ice-free season. Alternatively, the replicate surveys may take the

88 form of randomly-selected spatial replicates within the sample site. Spatial replication is relatively less

89 costly than multiple site visits, but occupancy of each replicate must be independent of the other

90 replicates within the site (Hines et al. 2010), and there must be uniform availability of the species for

91 detection in all spatial sub-units of an occupied site (Kendall and White 2009). These assumptions may

92 be violated when, for example, fish exhibit non-random spatial distributions due to schooling behaviour 
or when they are subject to downstream displacement in stream ecosystems during high water flow events. As a result of the potential for violation of assumptions, some authors have cautioned against the use of spatial replicates instead of temporal replicates (Kendall and White 2009), yet the actual amount of bias induced by use of spatial replicates in an occupancy study has rarely been quantified using real data. Occupancy models that include a first-order Markovian occupancy process (Gillespie 1992), in which the probability of occupancy in a spatial replicate $j$ depends on whether the species was present or absent from the previous spatial replicate $j-1$, have been developed (Hines et al. 2010) to handle issues where replicate spatial surveys suffer from a sequential form of spatial autocorrelation, such as may be present when replicates are constrained to linear landscape features like streams. The probability of detecting a species can also be influenced by the sampling method used (Nichols et al. 2008). Backpack electrofishing and visual counts from streambanks are two commonly used fish detection techniques. The relative efficiency of these two methods in producing abundance estimates is well-characterized (Bozek and Rahel 1991), however, their efficiency in collecting presenceabsence data for occupancy studies has not been addressed. Both techniques can suffer from bias resulting from fish size and behaviour, and can only be used in relatively shallow, $(<1 \mathrm{~m})$ clear water (Ensign et al. 2002). Electrofishing techniques require less observer standardization, but the electrical current can harm fish (Dwyer and White 1997, Reynolds 1996). Streamside visual surveys are less likely to result in altered behaviour or harm to fish (Brewer and Ellersieck 2011), but the identification of cryptically-coloured fish from the stream bank requires a greater level of skill (Bozek and Rahel 1991). Electrofishing gear is typically heavy (10-15 kg), expensive, and can be difficult to use in remote, rugged terrain, whereas streamside visual surveys do not require the operator to enter the water (when streams are narrow enough) and do not require any specialized equipment (Bozek and Rahel 1991). 
Occupancy models were developed using field observations of adfluvial young-of-year Arctic

116 Grayling near a diamond mine development in the Northwest Territories, Canada (DeBeers' Gahcho

117 Kué). The objectives of this study were to quantify bias in occupancy models that results from

118 alternative sampling methods, and specifically compare: 1) models of data derived from surveys of

119 sequential, adjacent spatial replicates to models of data derived from randomly-selected spatial

120 replicates; 2 ) relative detection probabilities of two commonly used observational techniques for

121 freshwater fishes (backpack electrofishing vs. streamside visual); 3) relative efficiency of using only

122 spatial vs. only temporal replicates to estimate site occupancy; and, 4) using the best models, examine

123 Arctic Grayling young of-year occupancy patterns in streams as they related to habitat characteristics

124 and industrial activities.

125

126 Methods

127 Case study area

The Kennady Lake drainage system is located approximately $280 \mathrm{~km}$ north northeast of

129 Yellowknife, Northwest Territories, Canada $\left(63^{\circ} 26^{\prime} 15 \mathrm{~N}, 109^{\circ} 11^{\prime} 51 \mathrm{~W}\right.$ ) (Fig. 1) within the sub-Arctic

130 Tundra Shield ecozone. Situated north of the treeline, it is part of a vast area commonly referred to as

131 the Barrenlands region; a semi-arid sub-arctic landscape with low levels of precipitation (between 200-

$132300 \mathrm{~mm}$ annually - over half of which falls as snow; (Environment Canada 1991)). The development of a

133 new open-pit diamond mine (Gahcho Kué), required draining a section of Kennady Lake. Prior to

134 development, Kennady Lake provided overwintering habitat for an adfluvial population of Arctic

135 Grayling, as well as several other fish species. The adfluvial Arctic Grayling in this system likely will

136 continue to use the undrained portion of Kennady Lake as overwintering habitat, in addition to several

137 other downstream chain lakes. The study area encompassed Barrenland streams ranging $90-800 \mathrm{~m}$ in 
138 length, with each end connected to lakes, over approximately $100 \mathrm{~km}^{2}$. The study area includes streams 139 within the Kennady Lake drainage basin, the Kirk lake drainage basin and the Walmsley Lake drainage 140 basin in the Northwest Territories of Canada.

142 Field survey methods

Prior to the start of the dewatering of Kennady Lake in 2014, baseline data of occupancy of

144 Arctic Grayling young-of-year in streams were collected. Sixty-seven stream segments (segments=spatial 145 replicates of streams that were each $30 \mathrm{~m}$ in length) in nine streams (KLM system; Fig. 1) downstream of 146 Kennady Lake were surveyed four times each during the summer of 2014. In summer 2015, after lake 147 dewatering had begun, 105 segments in 20 streams were surveyed up to three times in three areas: i) 148 streams immediately downstream of Kennady Lake, now affected by dewatering (the original KLM 149 systems, $\mathrm{n}=9$ streams); ii) streams further downstream of Kennady Lake but less likely to have been 150 affected by dewatering (the $P$ system, $n=5$ streams); and, iii) streams in a reference watershed not 151 affected by dewatering, downstream of Walmsley Lake (the W system; $n=6$ streams) (Fig. 1). To quantify the bias introduced to spatially-replicated stream occupancy models by organisms 153 exhibiting a lack of independence in their spatial distribution (project objective 1), sequential adjacent 154 stream segments were surveyed in 2014. The entire length of each stream in the KLM system was 155 surveyed in 30-m segments, of all streams (which served as the spatial replication within the stream) 156 (see Fig. S1a in Supporting Information). Results were compared to those generated by surveying a 157 random selection of segments in 2015; up to six stratified, randomly-selected 30-m segments were 158 surveyed in each stream (Fig. S1b) instead of entire streams. It was necessary to collect these data sets 159 in separate years for them to be considered independent, where a posteriori resampling of the data would be equivalent to non-parametric bootstrapping (Efron and Tibshirani 1994), which tends to return 
161 the same point estimate as the original data (Kendall and White 2009). To compare relative efficiency of

162 using spatial vs. temporal replicates to estimate stream occupancy (objective 3), we collected both

163 spatially-replicated and temporally-replicated survey data in each survey year (Fig. S1a and b).

To quantify the detection efficiency of two common fish detection techniques (project objective

2), we used both techniques to independently detect fish in all surveys. Field surveys were conducted by

moving upstream from the furthest downstream end of each stream. Polarized sunglasses were worn

167 during surveys to reduce glare from the water surface. Streamside visual surveys were conducted from

168 streambanks. Observations were conducted by two observers simultaneously from opposite banks of

169 the stream. These surveys were combined to a single observation of presence or absence of Arctic

170 Grayling young-of-year was recorded for each stream segment (i.e. each spatial replicate). Quantitative

171 estimates of variables that may affect the probability of detection were recorded, including cloud cover

172 and surface visibility (glare and turbulence; see Table S1). Starting again at the furthest downstream end

173 of each stream, single-pass electrofishing surveys were conducted moving upstream using a Smith-Root

174 LR-20B backpack electrofisher with a 6-inch anode ring (Voltage - 990 V; Duty Cycle - 50\%; Frequency -

$17535,0.20$ A output). The backpack operator and netter moved upstream together using a zig-zag pattern

176 to shock fish, sampling micro-habitats proportionally. Low specific conductivity of stream water (10-15

$177 \mu \mathrm{S} \mathrm{cm}^{-1}$ ) limited the effective range of the electrofisher to approximately $2 \mathrm{~m}$. Presence or absence of

178 Arctic Grayling young-of year was recorded for each 30-m stream segment.

Habitat variables hypothesized to affect occupancy or detection of Arctic Grayling young-of-year

were collected from each stream. Covariates that were expected to affect detection of fish were

181 assessed at the scale of the individual survey (see Table S1), whereas covariates expected to affect the

182 occupancy of fish in streams were measured at each stream segment (except discharge and distance to

183 overwintering habitat), and averaged to produce a single value representative of the entire stream. 
184 Proportion of stream margins with floodplain wetlands (defined as the presence of shallow, standing

185 surface water over hydric soils, adjacent to the main stream channel, (Tiner 1999)), proportion of stream 186 margins with undercut banks (defined as a stable bank which overhangs a stream (Dohner et al. 1997), 187 and percent cover of vegetation types (emergent, submerged and good overhanging vegetation (Nielson 188 and Johnson 1983)) were estimated visually. Stream width (tape measure), depth, and velocity (Hach 189 FH950 handheld flow meter mounted on a wading rod) were also quantified. Distance to overwintering 190 habitat was assessed as the minimum number of lake crossings required for Arctic Grayling young-of191 year to reach lakes with overwintering habitat (<4 m in depth which included Kennady Lake, Lake M4, 192 Lake 410, Kirk Lake and Walmsley Lake). Discharge was assessed using the United States Geological 193 Survey mid-section method (adapted from (Buchanan and Somers 1969) at a single fixed location for 194 each stream. All covariates were standardized to z-scores prior to analysis and checked for excessive 195 collinearity. Those found to be highly correlated (correlations $\geq 0.50$ ) were not included together in a 196 single model, but considered only in competing models to prevent overestimation of probability of 197 occupancy or detection.

\section{Statistical analysis}

Following MacKenzie et al. (2002), models of probability of Arctic Grayling young-of-year occupancy in streams (herein the term "probability of occupancy" will always refer to occupancy of

202 Arctic Grayling young-of-year in streams, unless otherwise specified) were assessed using the occupancy 203 modeling estimation and information theoretic approach. To estimate the relative utility of using 204 sequential spatial replicates vs randomly-selected spatial replicates (objective 1), and the relative utility 205 of using visual surveys vs. electrofishing surveys (objective 2), we modelled the probability of occupancy of Arctic Grayling young-of-year with hierarchal models that utilized all data from spatially- and 
207

208

209

210

211

212

213

214

215

216

217

218

219

220

221

222

223

224

225

226

227

228

229

temporally-replicated surveys (data configurations shown in Fig. S1 a and b) for each observational technique (visual and electrofishing) and for each year (2014 and 2015). Four hierarchical data sets were created and used in modelling: 2014-visual hierarchical, 2014-electrofishing hierarchical, 2015-visual hierarchical and, 2015-electrofishing hierarchical. Each of these four data sets was modeled by testing the relative fit of three $a$ priori candidate model structures and evaluated using the adjusted Akaike information criterion ( $\mathrm{AlC}_{\mathrm{c}}$; using the number of stream segments as the sample size). The difference in $\mathrm{AlC}_{\mathrm{c}}$ values was used to provide a relative weight-of-evidence for each candidate model structure $\left(\mathrm{w}_{\mathrm{i}}\right)$ for each data set. All modeling was performed using the program PRESENCE v10.7 (Hines 2006).

The first candidate hierarchical spatial-temporal model structure was a simple "multi-season"style model, $[\psi(),. \gamma(),. \varepsilon(),. p()$.$] , (referred to as Candidate Model 1: Open Occupancy, see Supplemental$ Data S1 in Supporting Information for more details on each of the candidate models and explanations of variables). These models are typically used when surveys are repeated annually (or "seasons"), but in the present study we treated each survey period within each of 2014 and 2015 as a "season". Spatial replication within each season was used to assess probability of detection, and results were used to provide guidance on the most appropriate timing for surveys if only one spatially-replicated survey were to be conducted in each year. Two additional candidate models were used to approximate a possible lack of independence in occupancy of segments within streams, which would test whether spatial heterogeneity of fish in the streams existed, and was not explained by habitat covariates, and if the randomly-selected spatial replicates survey style alleviated spatial dependency. A multi-scale occupancy model, $[\psi(),. \theta$ (segment), $p()$.$] , (referred to as Candidate Model 2: Clustered Spatial Correlation) was$ used to approximate nested spatial scales in the sampling design; stream segments $(\theta)$ were nested within streams $(\psi)$, and streams were nested within survey period. A multi-season Markovian occupancy model structure, $\left[\psi(),. \theta_{0}(),. \theta_{1}(),. \gamma(),. \varepsilon(),. p(),. \theta_{0} * \pi(=0)\right]$, (referred to as Candidate Model 3: Sequential 
Spatial Correlation with Open Occupancy) was used to test downstream spatial autocorrelation in the occupancy of replicate segments within streams. In this model, a first order Markovian spatial process is used; the probability of occupancy of Arctic Grayling young-of year in a stream is decomposed into three components - occupancy, $\psi$, and two availability variables given absence or presence in the adjacent stream segment, $\theta_{0}$ or $\theta_{1}$, respectively (Hines 2010).

The relative rankings of the three candidate models described above were used to address objective 1. If spatial heterogeneity existed in the occupancy of fish in streams, then candidate model 2 237 (clustered occupancy) or 3 (sequentially clustered occupancy) should rank highest by AIC for the 2014238 visual hierarchical and the 2014-electrofishing hierarchical data sets in which sequential spatial surveys 239 were used (Hines et al. 2010). If spatial heterogeneity exists in the occupancy of fish in the study 240 streams, and the use of randomly-selected spatial replicated surveys, as were used in 2015, ameliorated 241 the effect of this spatial heterogeneity, then candidate model 1 (open occupancy-no clustering in 242 occupancy) should rank as the highest model by AIC for the 2015-visual hierarchical and 2015243 electrofishing hierarchical data sets, suggesting that randomly-selected spatial segments may be a useful 244 survey design for Arctic stream fish.

246 benchmark hierarchical model was produced for each of the 4 data sets using a sequential model247 building strategy to account for non-random (i.e., resulting from biological or measurement covariates) 248 variation in probability of occupancy or detection. The probability of occupancy was modelled as a 249 function of stream-level biological covariates, and the probability of detection was modelled as a 250 function of segment-level measurement parameters. First, a detection $(p)$ model was built using all 251 subsets of covariates for the detection parameter (2014=2 detection covariates, 4 models; 2015=4 252 detection covariates, 16 models), while holding all other model parameters constant. Occupancy models 
were then constructed using all covariates singly (due to small sample sizes) on the large-scale

254 occupancy parameter, $\psi$ (2014=12 covariates, 48 models; 2015=8 covariates, 32 models), while holding

$255 \quad p$ at the most parsimonious model. Multi-model inference was achieved by averaging $\beta$ parameter

256 estimates and estimated probability of occupancy of streams $(\psi)$ of all models having $\Delta \mathrm{AIC}_{\mathrm{c}}$ estimates

257 within 2 of the top-ranked model (Richards 2005). Unconditional standard errors were estimated using

258 the delta method (Falke et al. 2012). The importance of covariates was estimated based on the relative

259 difference of model-averaged $\beta$ estimates from zero ( $0=$ no importance). Beta coefficients for these

260 benchmark hierarchical models are presented in Table S2 in the Supporting Information.

261

Objective 2 of this study was assessed by comparing the mean ( $\pm 95 \%$ confidence intervals)

262 probabilities of detection of Arctic Grayling young-of-year produced by the best 2014-visual hierarchical

263 model vs. the best 2014-electrofishing hierarchical model, and by comparing probabilities of detection

264 produced by the best 2015-visual hierarchical model vs. the best 2015-electrofishing hierarchical model.

265 Because we cannot know the true probability of detecting Arctic Grayling young-of-year, we were only

266 able to assess how similar the probabilities of detection for each observational method were to each

267 other and how small the range of error was for each observational method. If the two observational

268 methods produced similar probabilities of detection within the same year, then the prudent choice of

269 the "best" observational method would be the one that is relatively less expensive in terms of effort and

270 money, and produces the smallest amount of error in the estimates pf probability of detection and

271 occupancy.

272 We addressed objective 3 by comparing relative amount of bias in probability of occupancy

273 produced from models applied to a simulated temporal-replicate-only data set (Fig. S1 c) vs a

274 representative spatial-replicate-only data set (Fig. S1 d). Data from the 2015 survey campaign were

275 used. Here, bias refers to differences in probability of occupancy relative to estimates produced by the 
276

277

278

279

280

281

282

283

284

285

286

287

288

289

290

291

292

293

294

295

296

297

298

assumed best (benchmark) hierarchical spatial-temporal model. To simulate a temporally-replicated data set, presence/absence data from each spatial replicate within a stream were condensed to a single presence/absence data point that represented the entire stream for each of the three sampling periods in 2015. This data set thus consisted of presence/absence data for 20 streams visited up to three times in 2015. To represent a spatially-replicated data set, data from the second sampling period of 2015 were used. This data set consisted of presence/absence data for 20 streams, with up to six segments surveyed without temporal replication. Four datasets were thus produced from the 2015 survey data, 2015visual-temporal only data (configuration c in Fig. S1), 2015-visual-spatial only data (configuration d in Fig. S1), 2015-electrofishing-spatial only data (configuration c) and, 2015-electrofishing-temporal only data (configuration d). Small sample size ( $n=9$ streams) precluded conducting the same analysis on data collected in 2014. Each of these data sets was modeled by evaluating the relative fit of two a priori candidate model structures using $\mathrm{AIC}_{\mathrm{c}}$, which were single season versions of the candidate models described in the previous model set. The two candidate models included a simple single-season model, $[\psi(),. p()$.$] , and a single-season with correlated detections model, \left[\psi(),. \theta_{0}(),. \theta_{1}(),. p(),. \theta_{0}^{*} \pi(=0)\right]$, and the sequential model-building strategy outlined earlier in the methods was used. Probabilities of occupancy produced by the best model of each of the 2015-visual-temporal only data (configuration c, Fig. S1) and 2015-visual-spatial only data (configuration d, Fig. S1) were compared to the probabilities of occupancy produced by the benchmark hierarchical model of the 2015-visual hierarchical data (configuration b, Fig. S1). This was accomplished by calculating the root mean square deviance (RMSD) \pm $95 \%$ confidence intervals. Again, we assumed that the benchmark hierarchical occupancy models produced the truest estimates of site occupancy. Similarly, probabilities of occupancy of streams produced by the best model of each of the 2015-electrofishing-temporal only data (configuration c, Fig. S1) and the 2015-electrofishing-spatial only data (configuration d, Fig. S1) were compared to the 
probabilities of occupancy produced from the benchmark hierarchical model of the 2015-electrofishing hierarchical data set (configuration b, Fig. S1).

AIC assumes that the candidate model set contains at least one model that fits the data adequately; AIC is used to select the best model, but this is no assurance that the selected model is a good model, and substantial lack of fit can lead to inaccurate inferences (Anderson et al. 1994). Given the relative novelty and complexity of the models used in this study, robust methods available for testing the goodness-of-fit of the models have not yet been developed (pers. communication, D. MacKenzie). A qualitative testing procedure was used to indirectly assess the goodness of fit of the $a$ priori candidate (or global) model for the hierarchical benchmark model selection for each of the 4 hierarchical data sets (Cooch 2012). If the fit of the benchmark global models (which contain all possible parameters) is adequate, all subsets of these models are assumed to also fit the data because they originate from the global model (Burnham and Anderson 2002). The quasi-likelihood estimation parameter (QAICc, (Wedderburn 1974) is typically calculated as a correction for overdispersion based on

312 the parametric bootstrapped goodness-of-fit chi-squared statistic $(\hat{c})$. We arbitrarily set the $\hat{c}$ to values

313 of 1 (perfect fit) to 3 (overdispersed), in increments of 0.25 , to see how this affected the relative ranking 314 of candidate models. By adjusting $\hat{c}$ to higher values, suggestive of a lack of fit of the models, the model

315 selection becomes more conservative, which tends to favour models with less parameters. If

316 overdispersion exists within the model set, the relative weightings and order of the candidate models

317 change with small changes in $\hat{c}$, indicating a lack of fit of the a priori model structures, and indicating

318 that the data may be too sparse for robust modelling. We found that the rankings of the $a$ priori 319 candidate sets did not change with changes in $\hat{c}$, lending some measure of confidence that the top320 ranked models were a reasonable fit for the data (Cooch 2012). 


\section{Results and discussion}

323 Occupancy modelling using sequential, adjacent spatial replicates vs. randomly-selected spatial 324 replicates

The most supported model of the 2014 visual and electrofishing hierarchical data sets was

Candidate Model 3: Sequential Spatial Correlation with Open Occupancy, indicating that sequential spatially replicated surveys of adjacent stream segments produced spatially auto-correlated data sets

(Table 1). The presence of Arctic Grayling young-of-year in each stream segment was likely influenced by the presence of young-of-year in the upstream segment. In 2015, the selection of random segments resulted in segments being separated by an average distance $20 \mathrm{~m}$ (or approximately 0.7 segments, where one segment=30 m). Spatial auto-correlation was apparently relieved by the random spatial

332 replicate selection process implemented in 2015, as the AIC analysis of the 2015 hierarchical data sets

333 (both visual and electofishing) indicated that the best supported model was Candidate Model 1: Open

334 Occupancy. Thus, when adjacent spatial replicates were surveyed, the presence of fish in these

335 replicates was not independent of the presence of fish in the upstream segment. However, when we

336 instead surveyed only a subset of randomly-selected, non-adjacent spatial replicates the spatial

337 dependence of the presence of fish in spatially replicated surveys was ameliorated. These findings

338 suggest that either the area occupied by an interacting group of Arctic Grayling young-of-year, or the

339 relative size of suitable summer rearing habitat patches used by groups of Arctic Grayling young-of-year

340 in a stream, could be larger than $30 \mathrm{~m}$ (the size of the segments used as replicates), but smaller than 50

$341 \mathrm{~m}$ (the average distance between replicates in 2015 plus the size of the replicate). The home range of

342 adfluvial populations of adult European Grayling (Thymallus thymallus, a sister species of the Arctic

343 Grayling) in streams has been observed to be approximately $75-100 \mathrm{~m}$, although daily movements

344 ranged between 15-18 m (Nykänen et al. 2004). The home range of adfluvial populations of Arctic 
345

346

347

348

349

350

351

352

353

354

355

356

357

358

359

360

361

362

363

364

365

366

367

Grayling appears to be less well characterized, but the typical size of cohesive groups of interacting Arctic Grayling young-of year in an Alaskan stream ranged between 4-52 m (Hughes and Reynolds 1994).

\section{Probability of detecting fish with visual vs. electrofishing observational methods}

In both 2014 and 2015, probabilities of detecting fish using streamside visual surveys were nearly identical to those using electrofishing surveys (Fig. 2A and 2B). Probability of detection with electrofishing surveys was $3.3 \%$ higher in 2014 and $3.4 \%$ lower in 2015 than with visual surveys ( $p=0.0004, n=4$ temporal replicates and $p=0.0003, n=3$ temporal replicates, respectively, paired t-tests). While these results are statistically significant, we believe that a $3-4 \%$ difference in detection probability is trivial, and that either survey method would produce similar quality of data. Overall, detection probability was higher but more variable in 2014, averaging $54 \pm 5 \%$, compared to $40 \pm 2 \%$ in 2015 . In the surveys performed prior to the start of the dewatering of Kennady Lake (2014 surveys), there was improved probability of detection at water velocities above $10 \mathrm{~cm} / \mathrm{s}$, and the effect of water velocity on detection was nearly identical between the two sampling methods (Fig. 2C). This may reflect the somewhat poor swimming ability of fry at higher water velocities. Small Arctic Grayling young-ofyear are poor swimmers and have previously been observed to prefer water velocities between $0-10 \mathrm{~cm}$ $\mathrm{s}^{-1}$ (Jones and Tonn 2004). At water velocities above this preferred range, Arctic Grayling young-of-year may have been easier to detect because they were less able to swim quickly to a refugium in the higher water velocities.

There was no apparent effect of water velocity on probability of detecting fish after the start of dewatering in 2015. Average water velocity in stream segments was higher in $2015\left(33 \mathrm{~cm} \mathrm{~s}^{-1}\right)$ than in $2014\left(8 \mathrm{~cm} \mathrm{~s}^{-1}\right)$, and was above the apparent threshold of $10 \mathrm{~cm} \mathrm{~s}^{-1}$ for maximum probability of detection in 2014 (Fig. 2C). The depth of stream segments was the only variable that appeared to affect probability 
of fish detection in 2015 (Fig. 2D). Observers likely had greater difficulty in detecting fish in deeper waters; the magnitude of this effect was greater for streamside visual surveys than for electrofishing surveys. Stream segment depths in the KLM system were on average $10 \mathrm{~cm}$ deeper in $2015(26-54 \mathrm{~cm})$ than in $2014(18-44 \mathrm{~cm})$, where $10 \mathrm{~cm}$ total was observed as the optimum water depth for Arctic

372 Grayling young-of-year in another Barrenlands stream system (Jones and Tonn 2004). There was likely

373 much less habitat of suitable depth available in 2015 , which may explain why depth affected probability

374 of detection in 2015 but not in 2014. The increase in water depth of the KLM streams in 2015 was likely

375 partially a result of mine operations; water from Kennady Lake was pumped across a berm into a lake

376 that drains into stream K5 (Fig. 1). Natural hydrological variability could also have affected stream depth.

377 Water depths in the KLM system in 2015 were within the range of water depths observed in the P and W 378 systems (see Table S1), and summer precipitation was higher in 2015 (at $79.2 \mathrm{~cm}$ ) than in 2014 (at 58.4

$379 \mathrm{~cm})$ (Environment Canada 2016). Summer precipitation can strongly influence runoff and flooding into 380 streams in the Barrenlands region (Marsh et al. 2008).

382 of occupancy than electrofishing methods. Although estimates of the probability of occupancy

383 generated by models of streamside visual surveys were more variable than those generated by

384 electrofishing surveys, the estimates of the probability of occupancy from streamside visual surveys 385 were overall more similar to the naïve observations of fish presence in streams (Fig. 3A and B), and 386 better able to distinguish sites where Arctic Grayling young-of-year appeared to be absent. Currently, 387 electrofishing is regarded as the most effective monitoring technique of fish assemblages (Poos et al. 388 2007), however, the present study suggests that this convention may not hold when the monitoring goal 389 is landscape-scale presence-absence of fish, as opposed to estimates of abundance. While subtle 390 differences in the two observational methods were apparent, we think that ultimately, the visual and 
391 electrofishing surveys produced similar enough estimates of probabilities of both detection and

392 occupancy that they could be considered as equivalent methods in terms of quality of data produced.

393 However, the streamside survey method offers several logistical advantages. Streamside surveys are

394 much less likely to disrupt or injure to fish, the cost of purchase and transport of gear is minimal,

395 observers are not required to maneuver with heavy gear in the stream, and two observers can conduct

396 independent streamside surveys, effectively doubling the data produced per unit of survey effort. In

397 contrast, electrofishing surveys require two observers (an operator and a netter) to conduct a single

398 survey.

399

400

Relative bias in occupancy models when using spatially replicated surveys vs. temporally replicated

401 surveys

402 Estimates of probability of occupancy and detection produced from models of only spatially-replicated

403 data better represented the benchmark hierarchical models (having open occupancy) than models using

404 only the temporally-replicated data. Detection probabilities were comparable between the hierarchical

405 and spatially-replicated data sets ( $p$ of $\sim 0.50$ ), whereas the temporally-replicated data sets appeared to

406 have much higher detection probabilities than the benchmark hierarchical models (Fig. 4A). The

407 overestimation of detection probabilities in the temporally-replicated models likely resulted from

408 combining the data from all spatial replicates into a hypothetical single survey; the probability of

409 detection for the temporally-replicated model applies at the scale of the stream whereas the probability

410 of detection for the spatially-replicated and benchmark hierarchical models apply at the scale of the

411 spatial replicate; the30-m segment. As such, we do not suggest that differences in probability of

412 detection between spatially and temporally replicated models should be interpreted as one method

413 producing better probabilities of detection over the other. 
Both the single period of spatially-replicated surveys and the condensed temporally-replicated

415 surveys produced positively biased and more variable probabilities of occupancy of streams than the

416 benchmark hierarchical model. On average, models of the spatially-replicated streamside visual surveys

417 overestimated the proportion of streams occupied by $28.7 \pm 5 \%$ compared to the hierarchical

418 spatially/temporally-replicated model (Fig. 4B). Spatially-replicated electrofishing surveys overestimated

419 probabilities of occupancy by $32.1 \pm 9.4 \%$ compared to hierarchical spatially/temporally-replicated

420 electrofishing surveys (Fig. 4B). Temporally-replicated streamside visual and electrofishing surveys

421 resulted in greater overestimations of the probability of occupancy $(49.6 \pm 5.9 \%$ and $43.3 \pm 12.7 \%$,

422 respectively; Fig. 4B). Due to unequal sample sizes (spatial: $n=6$, and temporal: $n=3$ ) these results do not

423 necessarily disagree with previous occupancy studies, which report that spatial replication may not be a

424 robust substitute for temporal replicates (Kendall and White 2009). Models of the spatially-replicated

425 streamside visual survey data set were re-run using only 3 replicates, and the overestimation of the

426 probability that streams are occupied that was produced by the equalized replication of spatial surveys

427 increased from $28.7 \%$ to $40.3 \%$; however, this is still a better estimate of the probability of occupancy

428 than the temporally-replicated streamside visual surveys (at $49.6 \%$ overestimated probability of

429 occupancy relative to the benchmark model).

Bias (compared to the benchmark hierarchical models) in the estimates of probability of

431 occupancy was greater for streams in the system affected by the draining of the upstream lake (KLM

432 system) compared to the control (P and W) streams (Fig. 4B). Spatially-replicated streamside visual

433 surveys produced the most consistent (although still somewhat overestimated) estimates of probability

434 of occupancy of streams in the KLM system and the control streams. All other combinations of survey

435 method and replications failed to detect the probable decline in stream occupancy in the KLM system

436 resulting from alteration of water flow in the area downstream of Kennady Lake in 2015 (see presence 
437

438

439

440

441

442

443

444

445

446

447

448

449

450

451

452

453

454

455

456

457

data in Fig 3). In any monitoring scenario, detecting even small declines in affected populations of animals is of paramount importance. Given the relatively higher quality data produced at lower financial and human costs, when the hierarchical spatial/temporal survey style is not economically feasible, the recommended survey method for detecting changes in the occupancy of streams by Arctic Grayling young-of-year is streamside visual surveys.

\section{Lake dewatering effects on downstream populations of Arctic Grayling}

Results from the hierarchical model showed that during the summer of 2014, prior to the dewatering of the upstream Kennady Lake, the probability that streams in the KLM system were occupied by Arctic Grayling young-of-year was on average 78 - 89\% (Fig. 3A) (each data range in this section gives the estimate from the streamside visual method followed by the estimate from the electrofishing method from the hierarchical model). There was a $28-38 \%$ chance that a stream would become unoccupied by fish between survey periods. There was a fairly narrow range of abiotic and biotic conditions in the KLM streams during the 2014 surveys (see Table S1); conditions were relatively uniform across streams and were well within the ranges reported by Jones \& Tonn (2004) as being suitable for use by young-of-year Arctic Grayling in Barrenland streams. Water velocity in streams early in the season (Fig. 5A) had the strongest influence on the probability of occupancy, with decreasing probability of occupancy as water velocities increased from 0.05 to $0.2 \mathrm{~m} / \mathrm{s}$. This is nearly identical to the findings of a previous study conducted on Arctic Grayling young-of-year (Jones and Tonn 2004). Overall, the ranges of ideal depths and velocities in streams in the KLM system in 2014 provided a great deal of suitable Arctic Grayling young-of-year rearing habitat.

After the start of the dewatering of Kennady Lake in 2015, the probability of streams being occupied by Arctic Grayling young-of-year in the affected streams (KLM system) was lower. The 
460 probability that streams were occupied was only 31-39\% (compared to $78-89 \%$ prior to dewatering).

461 There was negligible probability of occupancy in several streams of the KLM system, including K5 (the

462 first stream immediately downstream of Kennady Lake), and only very small portions of streams M3, M2

463 and M1 were likely to have been occupied (Fig. 3B). The probability of occupancy in the downstream

464 control P system and the unconnected control W system was higher than in the affected KLM system;

465 averaging $48-82 \%$ and $40-73 \%$ respectively, despite these streams having otherwise similar habitat

466 characteristics to the KLM system (see Table S1). Only one control stream, P8 had no observations of

467 Arctic Grayling young-of-year. Stream P8 was also the deepest $(60 \mathrm{~cm})$ and had the fastest average

468 water velocity $(1.02 \mathrm{~m} / \mathrm{s})$ of all the streams sampled in 2015 . Within the affected KLM system, stream

469 L1B had the highest probability of occupancy (94\%, Fig. 3B) and was also both the shallowest stream in

470 July (average of $24 \mathrm{~cm}$ ), and had the lowest amount of connected wetlands (16\%).

471 Greater water depths early in the open-water season (early July) likely reduced the probability

472 that Arctic Grayling young-of-year would occupy a stream throughout the summer of 2015 (Figs 5B and

473 5C). Unlike the conditions prior to dewatering in 2014, after dewatering activities had begun there was a

474 slightly positive relationship between increasing water velocity and Arctic Grayling young-of-year

475 probability of occupancy (Fig. 5C). Water velocities in 2015 were a great deal higher in the affected KLM

476 system than the previous year (see Table S1), although within the range of water velocities observed in

477 the two control (P and W) systems. Jones and Tonn (2004) reported that there was clearly a weaker

478 preference for optimal water velocities $\left(0.1 \mathrm{~m} \mathrm{~s}^{-1}\right)$ over optimal water depths $(10-20 \mathrm{~cm})$ for larger Arctic

479 Grayling young-of-year in Barrenlands streams. With shallow habitats in short supply, Arctic Grayling

480 young-of-year may have been forced to tolerate less optimal water flows in the shallowest areas of the

481 streams in favour of avoiding predators, such as Northern Pike, inhabiting deeper water. 
Although water flow in the affected streams in the KLM system in 2015 was within the range

observed in control streams, the area of wetlands surrounding the streams and amount of submerged vegetation (vegetation may have become submerged as water moved out laterally from the flooded streams) was higher in the affected KLM system than in the control streams. Where stream water was deeper, there was a greater prevalence of floodplain wetlands along the sides of the stream channel $\left(R^{2}=0.50\right.$, Fig. $\left.5 B\right)$, coincident with a declining probability that young-of-year Arctic Grayling were present in the stream. The area of wetlands surrounding the streams in the KLM system was much higher after lake dewatering began in 2015 (16-50\%) than prior to dewatering in 2014 (0-34\%). Given the relatively flat landscape, the excess discharge of water into the system as a result of the dewatering of Kennady Lake likely moved out laterally from streambanks of the affected KLM streams, to fill wetlands instead of significantly increasing the depth of these streams. Based on the findings of this study, the persistence of this Barrenlands population of Arctic Grayling should be ensured if appropriate, site-specific targets of minimum, maximum and ideal water depths and velocities are established and closely monitored in streams immediately downstream of dewatering activities.

\section{Implications for monitoring}

The design of a cost-effective monitoring plan is crucial to the protection of animals in areas affected by anthropogenic activities. An occupancy-modelling framework was used to provide guidance on several common issues in the prediction of habitat use by a sentinel and valued species of fish, including imperfect detection, appropriate sampling methods and the best allocation of efforts spatially and temporally during very short seasons in difficult and remote terrain. Currently, we know of no other studies that have addressed issues of sequential spatial correlation in occupancy modelling of stream fish populations, given the inevitability that the standard method of observing fish while walking along 
505 the stream will produce spatially auto-correlated, and thus biased, estimates of site occupancy (Hines et 506 al. 2010).

508 young-of-year in these shallow streams. Given the minimal potential for injury to imperilled fish 509 populations, we recommend the use of the less invasive streamside visual survey method over 510 electrofishing for occupancy models of fish in non-turbid streams. The comparison of spatially-replicated 511 with temporally-replicated occupancy study designs showed that the spatially-replicated model 512 produced probabilities of occupancy that were the least biased compared to the (best) hierarchical 513 model. Most importantly, the spatially-replicated data set was capable of detecting the decline in the 514 probability of occupancy in the streams affected by mining operations, whereas the temporally515 replicated surveys could not. When there is a great need to survey large expanses of rough, remote 516 terrain, there is often a trade-off in allocation of effort. Facing a decision between spatially-replicated or 517 temporally-replicated surveys, we found that spatial replication can provide suitably sensitive, time and 518 cost-effective standardized data sets for modelling the probability of stream occupancy of Arctic fishes.

519 Surveys of adjacent stream segments produced spatially correlated data, as expected. This issue 520 was alleviated by surveying randomly-selected stream segments within a hierarchical spatially- and 521 temporally-replicated occupancy model. The assumption that a site is closed to changes in the 522 probability of occupancy in spatially-replicated surveys requires that the species' home range is similar 523 to the size of the site, such that the species is available for detection in all of the spatial replicates within 524 an occupied site (Kendall and White 2009). Positive bias in occupancy probabilities is commonly 525 observed in spatial surveys where sites are sampled exhaustively and/or without replacement (Kendall 526 1999, Kendall and White 2009), leading to the overestimation of occupancy probabilities. This can 527 increase the chances that a real decline in a population will go undetected. Currently, we know of no 
528 other studies that have addressed issues of sequential spatial correlation in occupancy modelling of

529 stream fish populations, given the near certainty that the standard method of observing fish while

530 walking along the stream will produce spatially auto-correlated, and thus biased, estimates of site

531 occupancy (Hines et al. 2010). Iterations of occupancy models have been designed to account for

532 violation of the assumption of independent observations (spatial-autocorrelation), and to account for

533 violation of the assumption of closure in time (staggered entry models), but there is no model that

534 allows for the violation of the assumption of closure in space. We suggest that it may be better to avoid

535 violating the spatial closure assumption by relaxing the effect of violating the assumption of

536 independence of spatial replicates. A downstream sequential survey style, but with replicate surveys

537 taking place immediately downstream of the first observation, might help to better meet the

538 assumption that fish are available in all segments, when present in the stream. Correlation in the

539 presence of Arctic Grayling young-of-year in sequential segments likely arises from the poor swimming

540 ability of a group of newly hatched fry that are easily displaced downstream during early larval stages

541 (Deleray and Kaya 1992).

542 The observed absence of young-of-year Arctic Grayling in some spatial replicates of otherwise

543 occupied streams suggests that they may use smaller suitable patches within a stream, as opposed to

544 occupying the entire length of a stream. If true, mitigating the effects of anthropogenic alterations of

545 water flow on whole streams may be less important than ensuring that a smaller portion of the stream

546 be maintained as suitable rearing habitat for Arctic Grayling young-of-year and that other portions of

547 the stream simply remain passable for fish migration.

548

549 Acknowledgements 
550 This study was funded by a DeBeers Canada Inc., a Collaborative Research and Development Grant from

551 the Natural Sciences and Engineering Research Council of Canada (to HKS), a Canadian Graduate

552 Scholarship from the Natural Sciences and Engineering Research Council of Canada (to K.J.A.), and a

553 Northern Scientific Training Program grant (to K.J.A.). The field program was executed with assistance

554 from S Lord, M Elwood, C Barrett, C Davis, D Swift, J Fregoe, S Catholique, J Remshardt, D Rusch, S

555 McLeod, C Marsh, and K Allen. M Servos and M Power provided helpful comments on an early draft of 556 this manuscript, and N Mochnacz and D Mackenzie aided with early study design.

\section{Data accessibility}

Data used in this study will be accessible from the University of Waterloo's institutional repository searchable from: https://uwspace.uwaterloo.ca/handle/10012/9937 (data will be deposited at time of

561 article acceptance with a direct address provided here).

562

\section{References}

564 Anderson, D.R., Burnham, K.P., and White, G.C. 1994. AIC model selection in overdispersed capturerecapture data. Ecology 75(6): 1780-1793. doi: 10.2307/1939637.

Bozek, M.A., and Rahel, F.J. 1991. Comparison of streamside visual counts to electrofishing estimates of Colorado River cutthroat trout fry and adults. N. Am. J. Fish. Manage. 11(1): 38-42.

Brewer, S.K., and Ellersieck, M.R. 2011. Evaluating two observational sampling techniques for determining the distribution and detection probability of age- 0 smallmouth bass in clear, warmwater streams. N. Am. J. Fish. Manage. 31(5): 894-904. doi: 10.1080/02755947.2011.611067. 
572 Buchanan, T.J., and Somers, W.P. 1969. Chapter A8: Discharge measurements at gaging stations. In

573 Techniques of Water-Resources Investigations of the United States Geological Survey. United $574 \quad$ States Geological Survey, Washington, DC, USA.

575 Burnham, K.P., and Anderson, D.R. 2002. Model selection and multimodel inference: A practical 576 information-theoretic approach (2nd ed.). Springer-Verlag, New York, NY, USA.

577 Cooch, E.G. 2012. Program MARK: A gentle introduction. Cornell University, Ithaca, NY, USA.

578 Deleray, M.A., and Kaya, C.M. 1992. Lakeward and downstream movements of age-0 Arctic Grayling (Thymallus arcticus) originating between a lake and a waterfall. The Great Basin Naturalist 52(4): 344-351.

Dohner, E., Simpson, J., Byrne, J., Dates, G., and Mayio, A. 1997. Volunteer Stream Monitoring: A Methods Manual. Office of Water, USA Environmental Protection Agency Washington, DC.

Dwyer, W.P., and White, R.G. 1997. Management briefs: Effect of electroshock on juvenile Arctic Grayling and Yellowstone cutthroat trout growth, 100 days after treatment. N. Am. J. Fish. Manage. 17(1): 174-177. doi: 10.1577/1548-8675(1997)017<0174:MBEOEO>2.3.CO;2.

Efron, B., and Tibshirani, R.J. 1994. An introduction to the bootstrap. CRC press, Boca Raton, FL, USA.

Ensign, W.E., Temple, A.J., and Neves, R.J. 2002. Effects of fright bias on sampling efficiency of stream fish assemblages. J. Freshwat. Ecol. 17(1): 127-139. doi: 10.1080/02705060.2002.9663876.

Environment Canada. 1991. Canadian climate normals 1961-1990. Available from http://climate.weather.gc.ca/climate_normals/index_e.html [accessed May 30 2016]. 2016]. 
594 Falke, J.A., Bailey, L.L., Fausch, K.D., and Bestgen, K.R. 2012. Colonization and extinction in dynamic 595 habitats: An occupancy approach for a Great Plains stream fish assemblage. Ecology 93(4): 858867. doi: 10.1890/11-1515.1.

Gillespie, D.T. 1992. Markov processes: an introduction for physical scientists. Academic Press Ltd, San Diego, CA.

599

600

601

602

603

604

605

606

607

608

609

610

612

613

614

Gu, W., and Swihart, R.K. 2004. Absent or undetected? Effects of non-detection of species occurrence on wildlife-habitat models. Biol. Conserv. 116(2): 195-203. doi: 10.1016/S0006-3207(03)00190-3.

Hines, J.E. 2006. PRESENCE- Software to estimate patch occupancy and related parameters. Patuxent, MD: United States Geological Survey - Patuxent Wildlife Research Center.

Hines, J.E., Nichols, J.D., Royle, J.A., MacKenzie, D.I., Gopalaswamy, A., Kumar, N.S., and Karanth, K. 2010. Tigers on trails: Occupancy modeling for cluster sampling. Ecol. Appl. 20(5): 1456-1466.

Hughes, N.F., and Reynolds, J.B. 1994. Why do Arctic Grayling (Thymallus arcticus) get bigger as you go upstream? Can. J. Fish. Aquat. Sci. 51(10): 2154-2163. doi: 10.1139/f94-216.

Jones, N.E., and Tonn, W.M. 2004. Resource selection functions for age-0 Arctic Grayling (Thymallus arcticus) and their application to stream habitat compensation. Can. J. Fish. Aquat. Sci. 61(9): 1736-1746. doi: 10.1139/f04-116.

Kendall, W.L. 1999. Robustness of closed capture-recapture methods to violations of the closure assumption. Ecology 80(8): 2517-2525. doi: 10.2307/177237.

Kendall, W.L., and White, G.C. 2009. A cautionary note on substituting spatial subunits for repeated temporal sampling in studies of site occupancy. J. Appl. Ecol. 46(6): 1182-1188. doi:

10.1111/j.1365-2664.2009.01732.x. 
615

616

617

618

619

620

621

622

623

624

625

626

627

628

629

630

631

632

633

634

635

636

637

MacKenzie, D.I., Nichols, J.D., Lachman, G.B., Droege, S., Royle, J.A., and Langtimm, C.A. 2002. Estimating site occupancy rates when detection probabilities are less than one. Ecology 83(8): 2248-2255. doi: $10.2307 / 3072056$.

Marsh, P., Pomeroy, J., Pohl, S., Quinton, W., Onclin, C., Russell, M., Neumann, N., Peitroniro, A., Davison, B., and McCartney, S. 2008. Snowmelt processes and runoff at the Arctic treeline: Ten years of MAGS research. In Cold Region Atmospheric and Hydrological Studies, The Mackenzie GEWEX experience Volume 2: Hydrologic Processes. Edited by M.-k. Woo. Springer-Verlag, New York, NY, USA. pp. 97-123.

Nichols, J.D., Bailey, L.L., Talancy, N.W., Campbell Grant, E.H., Gilbert, A.T., Annand, E.M., Husband, T.P., and Hines, J.E. 2008. Multi-scale occupancy estimation and modelling using multiple detection methods. J. Appl. Ecol. 45(5): 1321-1329.

Nielson, L.A., and Johnson, D.L. 1983. Sampling considerations. In Fisheries Techniques. Edited by L.A. Nielson and D.L. Johnson. American Fisheries Society, Bethesda, MD, USA. pp. 1-21.

Nykänen, M., Huusko, A., and Lahti, M. 2004. Changes in movement, range and habitat preferences of adult grayling from late summer to early winter. J. Fish Biol. 64(5): 1386-1398. doi: 10.1111/j.0022-1112.2004.00403.x.

Poos, M.S., Mandrak, N.E., and McLaughlin, R.L. 2007. The effectiveness of two common sampling methods for assessing imperilled freshwater fishes. J. Fish Biol. 70(3): 691-708. doi: 10.1111/j.1095-8649.2007.01349.x.

Prowse, T., Alfredsen, K., Beltaos, S., Bonsal, B.R., Bowden, W.B., Duguay, C.R., Korhola, A., McNamara, J., Vincent, W.F., Vuglinsky, V., Walter Anthony, K.M., and Weyhenmeyer, G.A. 2012. Effects of changes in Arctic lake and river ice. AMBIO: A Journal of the Human Environment 40(1): 63-74. doi: 10.1007/s13280-011-0217-6. 
638

639

640

641

642

643

644

645

646

647

648

649

650

651

652

653

654

655

656

657

658

659

660

Reist, J.D., Wrona, F.J., Prowse, T.D., Power, M., Dempson, J.B., Beamish, R.J., King, J.R., Carmichael, T.J., and Sawatzky, C.D. 2006a. General effects of climate change on Arctic fishes and fish populations. AMBIO: A Journal of the Human Environment 35(7): 370-380.

Reist, J.D., Wrona, F.J., Prowse, T.D., Power, M., Dempson, J.B., King, J.R., and Beamish, R.J. 2006b. An overview of effects of climate change on selected Arctic freshwater and anadromous fishes. AMBIO: A Journal of the Human Environment 35(7): 381-387. doi: 10.1579/00447447(2006)35[381:AOOEOC]2.0.CO;2.

Reynolds, J.B. 1996. Electrofishing. In Fisheries Techniques. Edited by B.R. Murphy and D.W. Willis. American Fisheries Society, Bethesda, MD, USA.

Richards, S.A. 2005. Testing ecological theory using the information-theoretic approach: Examples and cautionary results. Ecology 86(10): 2805-2814. doi: 10.1890/05-0074.

Royle, J.A., and Nichols, J.D. 2003. Estimating abundance from repeated presence-absence data or point counts. Ecology 84(3): 777-790. doi: 10.1890/0012-9658(2003)084[0777:eafrpa]2.0.co;2.

Scott, W.B., and Crossman, E.J. 1973. Freshwater fishes of Canada. Fisheries Research Board of Canada Bulletin.

Tiner, R.W. 1999. Wetland indicators: A guide to wetland identification, delineation, classification, and mapping. CRC Press, Boca Rata, FL, USA.

Wedderburn, R. 1974. Quasi-likelihood functions, generalized linear models, and the Gauss-Newton method. Biometrika 61(3): 439-447. doi: 10.1093/biomet/61.3.439.

Wrona, F.J., Prowse, T.D., Reist, J.D., Hobbie, J.E., Lévesque, L.M.J., and Vincent, W.F. 2006. Climate impacts on Arctic freshwater ecosystems and fisheries: Background, rationale and approach of the Arctic Climate Impact Assessment (ACIA). AMBIO: A Journal of the Human Environment 35(7): 326-329. doi: 10.1579/0044-7447(2006)35[326:CIOAFE]2.0.CO;2. 
661

\section{Figure Captions}

663 Fig. 1. Location of study area.

664

665 Fig. 2. Comparison of the detection probabilities $\pm 95 \% \mathrm{Cl}$ estimated from two common fish sampling

666 methods in A) 2014 and B) 2015. Detection probabilities were affected by C) water velocity (m/s) in 667 2014, and D) water depth (m) in 2015.

668

669

Fig. 3. Probability of occupancy \pm SE vs. observed presence of Arctic Grayling young-of-year in streams in

670 A) 2014 and B) 2015 based on survey method.

671

672 Fig. 4. Relative bias in probabilities $\pm 95 \% \mathrm{Cl}$ of A) detection and B) occupancy produced by simulated 673 occupancy surveys of only spatial or only temporal replicates compared to the combined hierarchical 674 model including both spatial and temporal replication.

675

676

Fig. 5. Proportion of streams occupied modelled as a function of influential habitat variables based on

677 data from A) 2014 streamside visual surveys, B) 2015 streamside visual surveys, and C) 2015

678 electrofishing surveys. No habitat variables were found to significantly influence the probability of

679 occupancy of streams in 2014 electrofishing surveys.

680

681

682 
683 684 685 686 models.

687 Table S1. Ranges of sampled habitat variables.

688 689

690

691

692

693

694

695

696

697

698

699 700 701 702 703 704

\section{Supporting information}

Additional Supporting Information may be found in the online version of this article:

Supplemental Data S1. Description and rationale for use of a priori candidate hierarchical occupancy

Table S2. Beta coefficients for benchmark hierarchical models.

Fig. S1. Conceptual representation of the data configurations used of the analysis of presence-absence.

Table 1. Benchmark model selection results of a priori candidate models of the 2014-visual hierarchical, 2015-electrofishing hierarchical, 2015-visual hierarchical and, 2015-electrofishing hierarchical data sets of presence-absence of Arctic Grayling young-of-year in Barrenland streams. $\Delta \mathrm{AICc}$ (corrected for small sample size) of each model from the minimum model was used to calculate AICC weight $\left(w_{i}\right)$ and rank of each model, and to select the most parsimonious model from the three candidate structures. $\mathrm{K}$ is the number of model parameters, and $-2 \log (\mathrm{L})$ is the negative of twice the logarithm of the likelihood 
705 function evaluated at the maximum likelihood estimates. * indicates models that failed to converge

706 mathematically and were removed from consideration 


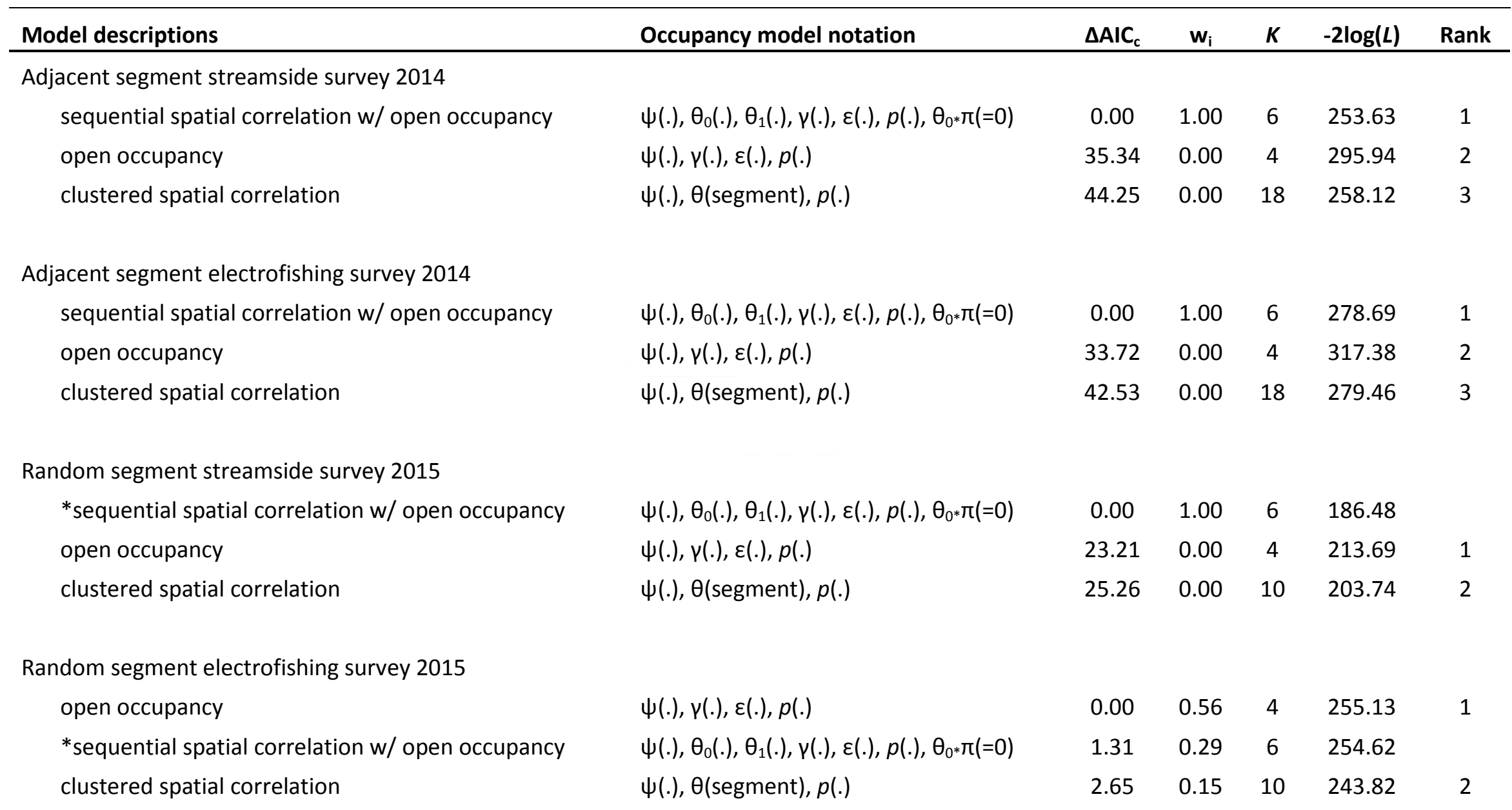

* Model notation is described in detail in the Supplemental data S1 of the Supporting Information. 
Fig. 1. Location of study area.

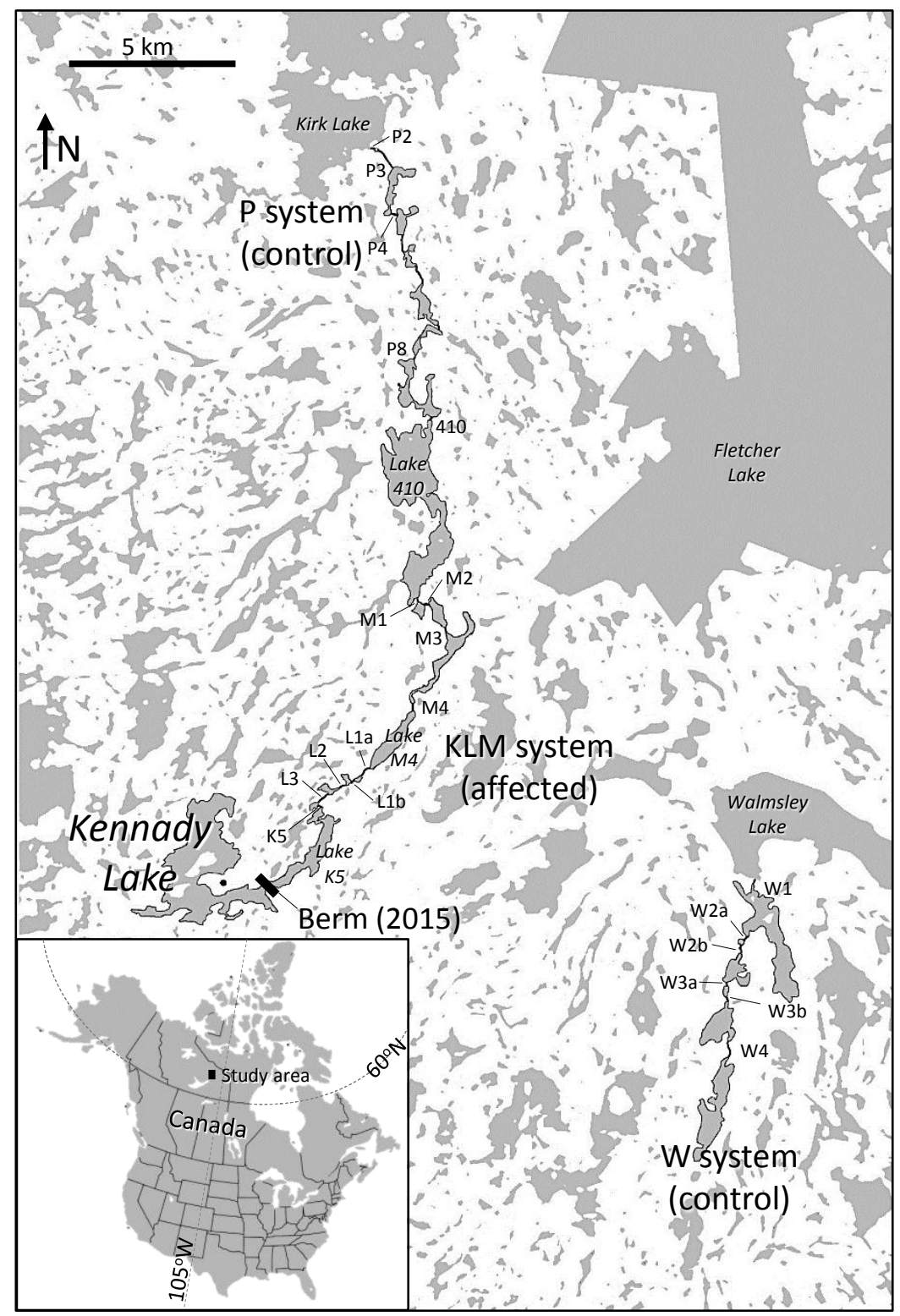

* Larger map adapted from Map data $\odot 2016$ Google. Inset map adapted from creative commons image, Lokal_Profil (CC-BY-SA-2.5). 
Fig. 2. Comparison of the detection probabilities $\pm 95 \% \mathrm{Cl}$ estimated from two common fish sampling methods in A) 2014 and B) 2015. Detection probabilities were affected by C) water velocity (m/s) in 2014, and D) water depth (m) in 2015.
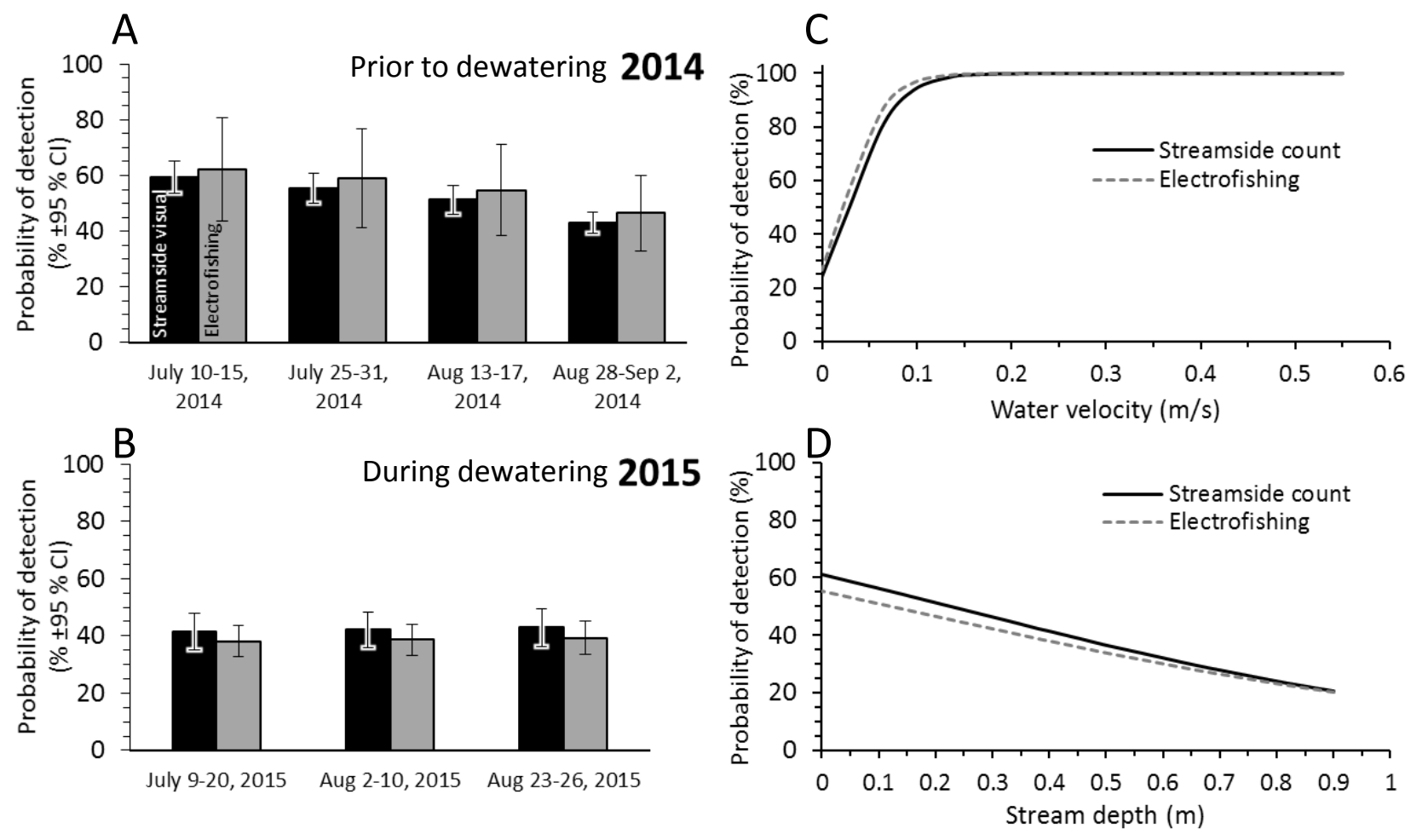
Fig. 3. Probability of occupancy \pm SE vs. observed presence of Arctic Grayling young-of-year in streams in A) 2014 and B) 2015 based on survey method.

A Prior to dewatering

A 2014

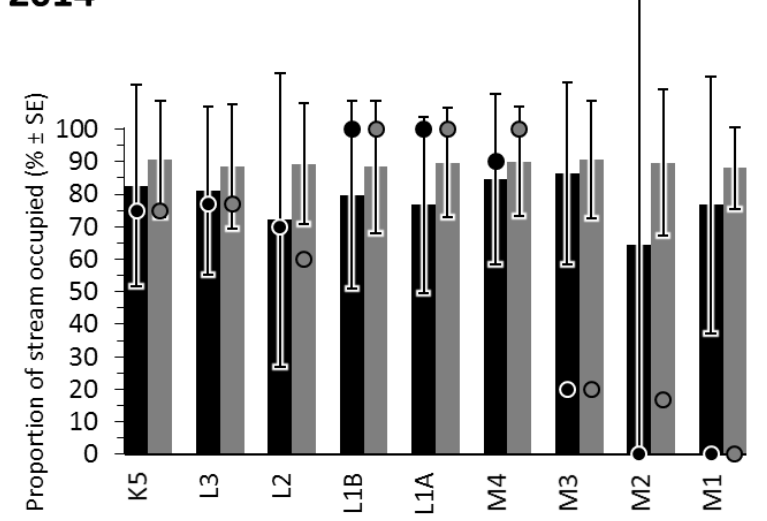

Occupancy: streamside visual

Occupancy: electrofishing

Presence: streamside visual

Presence: electrofishing

\section{During dewatering}

B

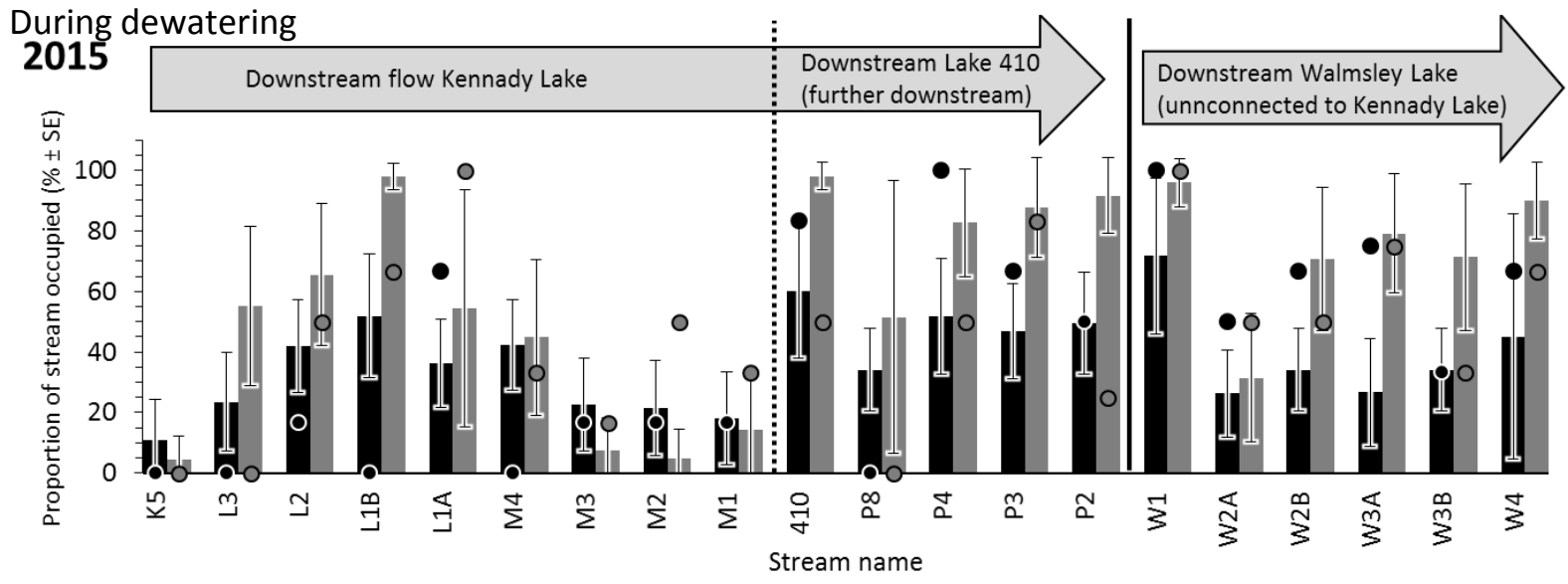


Fig. 4. Relative bias in probabilities $\pm 95 \% \mathrm{Cl}$ of A) detection and B) occupancy produced by simulated occupancy surveys of only spatial or only temporal replicates from 2015, compared to the combined hierarchical benchmark model including both spatial and temporal replication from 2015.
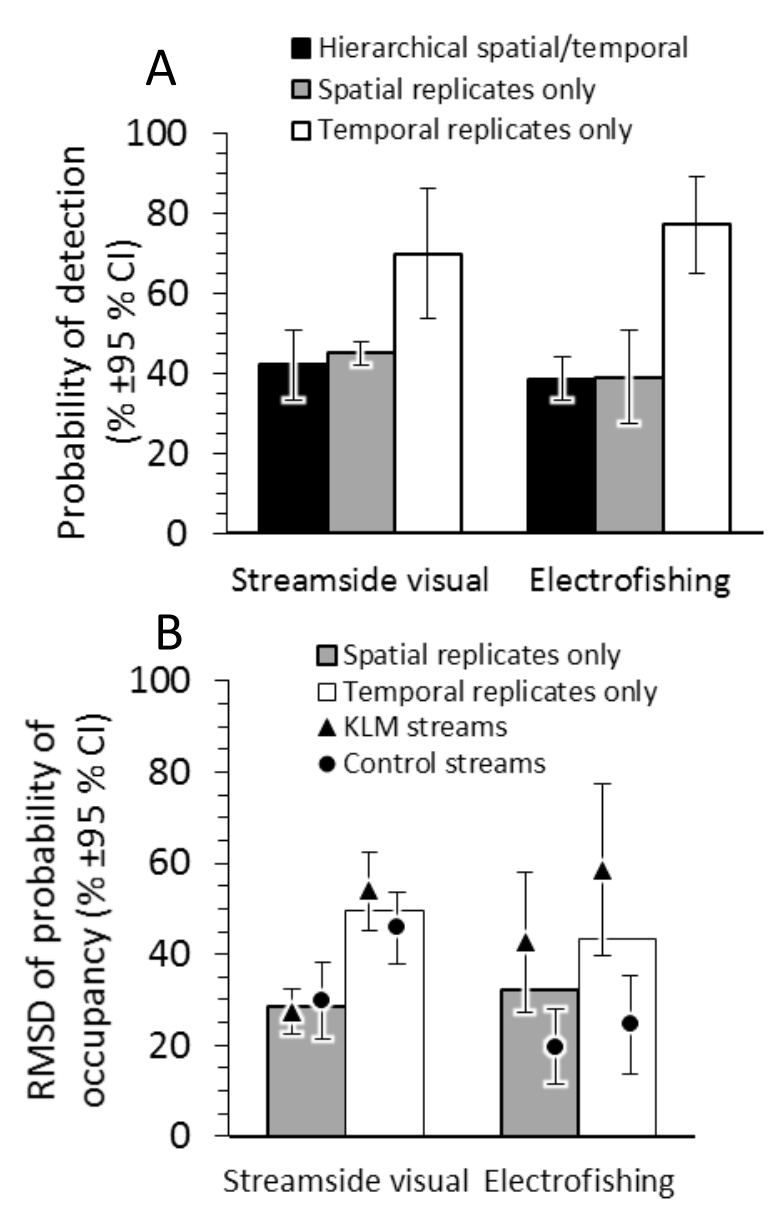
Fig. 5. Proportion of streams occupied modelled as a function of influential habitat variables based on data from A) 2014 streamside visual surveys, B) 2015 streamside visual surveys, and C) 2015 electrofishing surveys. No habitat variables were found to significantly influence occupancy in 2014 electrofishing surveys.

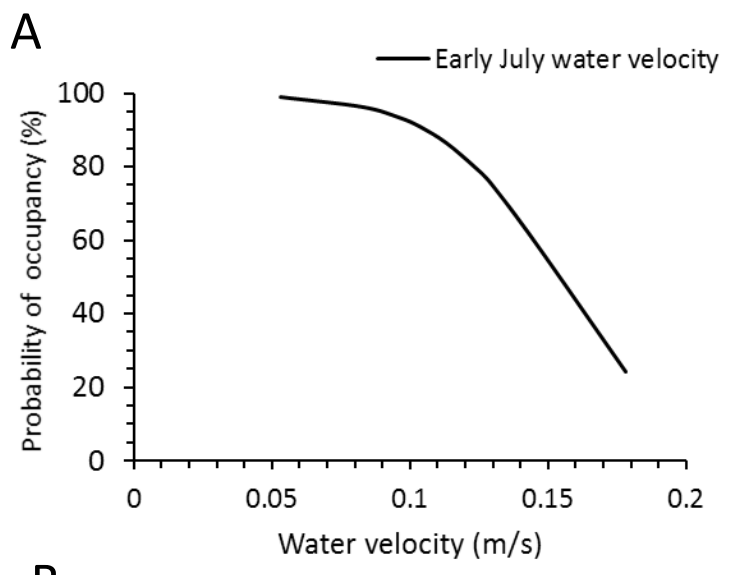

B
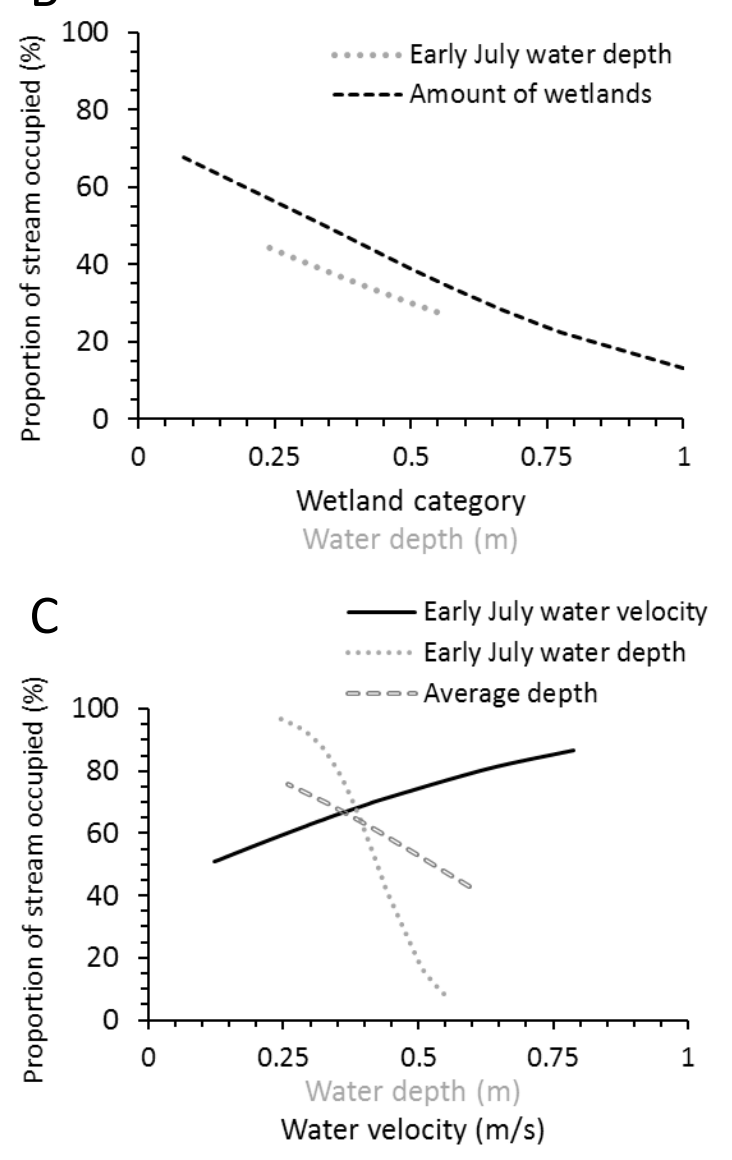